This PDF is a selection from a published volume from the National Bureau of Economic Research

Volume Title: The Economic Consequences of Demographic Change in East Asia, NBER-EASE Volume 19

Volume Author/Editor: Takatoshi Ito and Andrew Rose, editors

Volume Publisher: University of Chicago Press

Volume ISBN: 0-226-38685-6

ISBN13: 978-0-226-38685-0

Volume URL: http://www.nber.org/books/ito_08-2

Conference Date: June 19-21, 2008

Publication Date: August 2010

Chapter Title: Demographic Transition, Childless Families, and Economic Growth

Chapter Authors: Francis T. Lui

Chapter URL: http://www.nber.org/chapters/c8151

Chapter pages in book: (351 - 373) 


\title{
Demographic Transition, Childless Families, and Economic Growth
}

\author{
Francis T. Lui
}

\subsection{Introduction}

Demographic transition is a well-known phenomenon that has repeatedly taken place in many countries during the last few centuries. Although characterization of this phenomenon may vary among different authors, its main features can conveniently be summarized as follows. ${ }^{1}$ Before a society moves from stagnancy to sustained economic growth, there is often a significant improvement in the life expectancy of its population. In the early phase of the development process, population growth rate rises, not only because people live longer, but also because total fertility rate (TFR) may go up. In the more advanced stage of development, there is marked and continuous decline in fertility until it has hit a "minimum" level. ${ }^{2}$

Understanding the mechanics of demographic transition is important both from theoretical and policy perspectives. At the theoretical level, demographic transition is closely linked to the interaction between investments in quantity and quality of children, which is at the core of endogenous growth models. On policy grounds, changes in fertility rates can easily exert profound effects on many socioeconomic issues, such as education, health

Francis T. Lui is a professor of economics at the Hong Kong University of Science and Technology.

Financial support from the Research Grant Council of Hong Kong (Ref. No.: HKUST6466/ $06 \mathrm{H}$ ) is gratefully acknowledged. I am indebted to a group of able students for their research assistance. They are Amy Chan, Simon Chan, Steven Chong, Bing Han, Billy Ho, Angela Lam, Chang Liu, John Tian, and Kathy Yu. Lung-fei Lee, Ronald Lee, Siu-fai Leung, Hongbin Li, Roberto Mariano, participants of the nineteenth NBER-EASE, and two anonymous referees have provided valuable comments. They are not responsible for any errors that remain in this chapter.

1. See, for example, Coale (1987); Easterlin (1987); and Dyson and Murphy (1985).

2. See World Bank (1984, chapter 2). 
Total fertility rates in a sample of economies

\begin{tabular}{lll}
\hline & 1965 & 2008 \\
\hline Asia-Pacific Rim & & \\
$\quad$ Australia & 3.0 & 1.76 \\
China & 6.4 & 1.77 \\
Hong Kong & 4.5 & 0.98 \\
Japan & 2.0 & 1.22 \\
South Korea & 4.9 & 1.29 \\
Taiwan & & 1.13 \\
Thailand & 6.3 & 1.64 \\
$\quad$ Singapore & 4.7 & 1.08 \\
Developed economies & & \\
$\quad$ European Union & $2.7^{\mathrm{a}}$ & 1.5 \\
$\quad$ United States & 2.9 & 2.1 \\
World & 5.1 & 2.58 \\
\hline
\end{tabular}

Sources: Data for 2008 are from Central Intelligence Agency (2008). Data for 1965 are from World Bank (1992).

${ }^{\text {a The }} 1965$ TFR figure of 2.7 is for Organization for Economic Cooperation and Development (OECD) countries.

care, housing, immigration, retirement protection, business opportunities, saving behavior, and even international balance of payments. These effects are more prominent in economies where fertility rates deviate significantly from the population replacement ratio, which is roughly equal to 2.1 . Table 10.1 shows that in 2008 , average TFR in the world is 2.58 , which is well above the replacement ratio. ${ }^{3}$ The European Union, consisting of well-developed economies, expectedly, has a low TFR of 1.5. The United States, with a TFR as high as 2.1, is more an exception rather than a rule. On the other hand, the low TFRs in many economies in the Asia-Pacific Rim seem to indicate that they have already reached some advanced stages of demographic transition, even though the per capita income levels in some are still much lower than those in the United States or Europe. Comparisons with the 1965 figures readily show that these Asia-Pacific economies have undergone major declines in TFR in recent decades. In view of the possibility that low and declining TFRs can upset prevailing social and economic equilibria, it is useful for us to investigate the causes behind the demographic transitions in this region.

The low TFRs in East Asian countries indicate that the women there, on average, bear very few children. However, they do not explicitly tell us how many women choose not to bear any children at all. The importance of this matter is often overlooked. Parents can invest in their children's human capi-

3. The source for table 10.2 is CIA (2008). There are minor discrepancies between the data there and those from official government statistics. Since the errors are minor, we ignore them. 
tal only if they have children. If an adult chooses not to have any children; that is, the optimal quantity of children has a corner solution, the investment vehicle disappears. Endogenous growth models built upon such investment would lose much of their relevance. This problem would not be too important if only a small percentage of families choose to remain childless. However, as the evidence in the next section shows, up to 30 percent of the women in Hong Kong - an economy having one of the lowest TFRs in the worldwill never have any children, and this percentage is rising rapidly! Similar situations also occur in many other economies. Thus, the issue of childless families is not a trivial issue that can be ignored by model-builders.

The purpose of this chapter, which is part of a larger study on the demographic transition, is to identify the factors that have significant effects on fertility choices. The theoretical framework is a variant of the Ehrlich-Lui (1991) model. The empirical evidence is mainly based on the data collected in a survey that I conducted.

In the next section, I shall present the evidence to support the argument that zero fertility is a matter that we must reckon with. Section 10.3 briefly discusses a theoretical framework that can generate both the demographic transition and corner solution for fertility. Some testable hypotheses are stated. Section 10.4 outlines the approach for testing the hypotheses, and presents and discusses the empirical results. Concluding remarks are in section 10.5. Finally, some details of the survey are discussed in the appendix.

\subsection{The Prevalence of Childless Families}

In this section, I shall argue that the experiences of Hong Kong can serve as a "leading indicator" for the demographic transitions in East Asia and possibly other developed economies as well. I shall also provide estimates for the proportion of Hong Kong women who will remain childless throughout their lives.

There is now an extensive literature on the relationship between longevity and fertility, ${ }^{4}$ some of them showing that an increase in longevity can initiate the onset of the demographic transition. Life expectancy at birth in Hong Kong in 2006 was 85.6 years for women and 79.5 for men. ${ }^{5}$ Not only are these among the highest in the world, they also indicate substantial increases since 1981, when the corresponding figures were 78.5 and 72.3 , respectively. As such, it is not surprising to see that the median age of the Hong Kong population has risen from thirty-four in 1996 to thirty-nine in 2006. More importantly, the total fertility rate in Hong Kong, as evidenced in table 10.2, has also experienced a long and rapid decline episode. Table

4. Some examples, in chronological order, are Ehrlich and Lui (1991, 1997); Blackburn and Cipriani (2002); Boldrin and Jones (2002); Kalemli-Ozcan (2003); Doepke (2004, 2005); Zhang and Zhang (2005); and Soares (2006).

5. See table 1.4 of Census and Statistics Department (2007). 
Table 10.2

Total fertility rate in Hong Kong

\begin{tabular}{lcccccc}
\hline 1965 & 1970 & 1981 & 1991 & 1996 & 2001 & 2006 \\
\hline 4.5 & 3.3 & 1.95 & 1.30 & 1.20 & 0.93 & 0.98 \\
\hline
\end{tabular}

Sources: The 1965 and 1970 figures are from World Bank $(1992,1993)$. The 1981 to 2006 figures are derived from the age-specific fertility rates reported in table 2.6 of Census and Statistics Department (2007).

10.2 also shows that Hong Kong's TFR has fallen below one only in recent years. Back in 1965, it was as high as 4.5.

The slight increase in TFR in the last few years should not be interpreted as a reversal in trend. From 1998 to 2003, Hong Kong suffered from a prolonged deflationary recession. The fertility rate in that period, as recorded in the 2001 Census, was likely depressed to below trend level because of the unfavorable economic environment. Using arguments similar to Becker and Barro (1988), we expect that parents would try to make up for the "losses" of children when the economy improved again after 2003.

Given the low TFR in Hong Kong, we want to estimate the proportion of women who will have zero fertility in their entire lifetimes. The estimates are based on official census data of various years. These data also allow us to make some simple projections of what will happen in the near future.

Census data can provide information on the number of children that have already been born, but there is no direct information on what would happen to women's fertility decisions in the future. However, if a woman aged fortyfive does not have any children, we can reasonably expect that the chance for her to bear children in the future is negligibly small. Figure 10.1 plots the percentages of women at each age group from twenty to forty-five who have never borne any children for the years 1996, 2001, and 2006.

In 2006, the proportion of childless forty-five-year-old women is 29.22 percent. While this is already a very large proportion, we should note from figure 10.1 that the childless rates of women in every age group have been increasing from 1996 to 2006 . Table 10.3 provides further information on how these proportions change over time. For the forty-one to forty-five age group, the percentage of women having no children rises from 20.9 percent in 1996 to 31.81 percent in 2006, representing roughly an 11 percentage point increase for the ten-year period. Judging from the high proportion of younger women who do not have any children, a proportion that has also been increasing over time, we can safely project that in the next decade, the percentage of Hong Kong women who will remain childless throughout their lives can easily exceed one-third or even 40 percent of the adult female population.

As a robustness test for the estimate that in 2006, 31.81 percent of the women in the forty-one to forty-five years old age group do not have any children, we perform another estimate using a completely different data set; namely, data from a survey that we have conducted. Details of that survey 


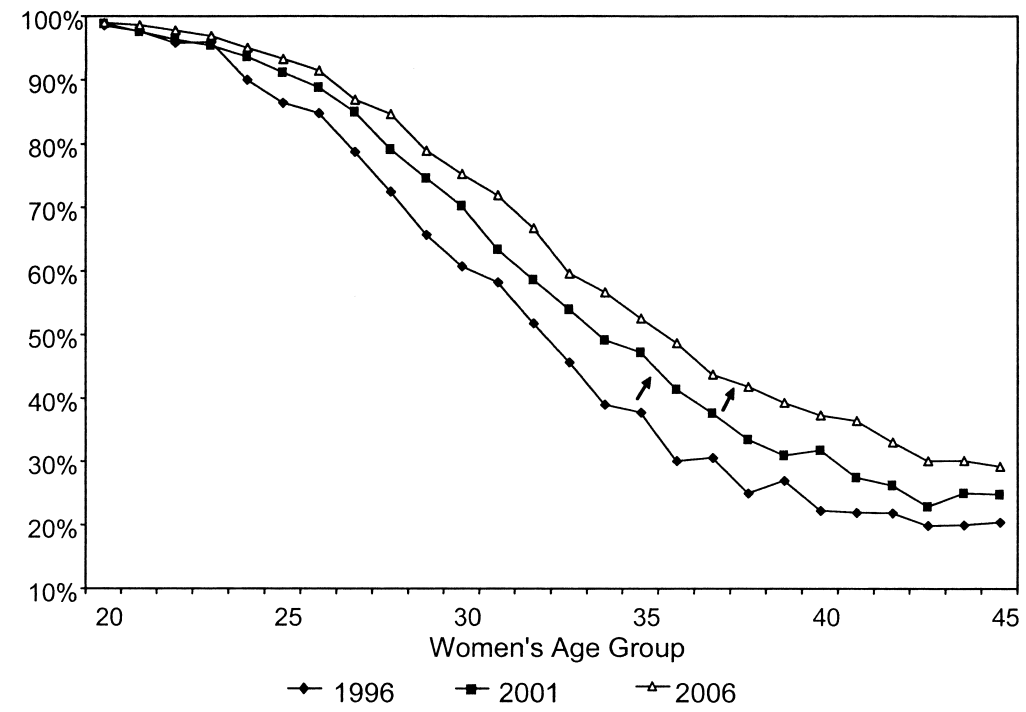

Fig. 10.1 Percentage of women who have no children

Table 10.3

Proportion of women at different age groups who do not have any children

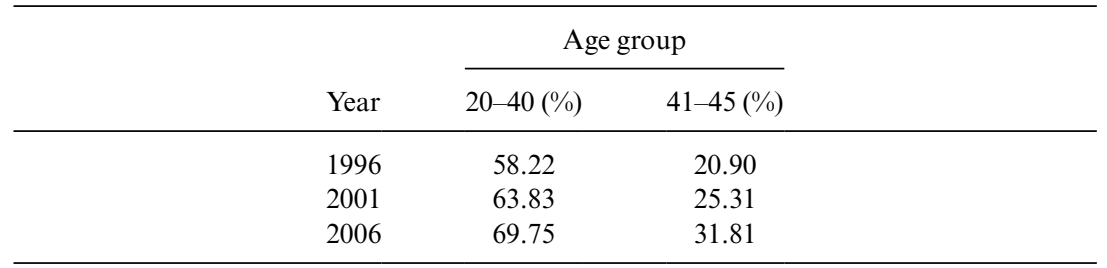

Sources: Figures for 2001 and 2006 are derived from the 5 percent samples of the 2001 and 2006 Hong Kong Census microdata. Figures for 1996 are derived from the 1 percent sample of the 1996 Hong Kong Census microdata. See Census and Statistics Department (1996, 2001, 2006).

are discussed in the appendix. The survey provides information, among others, on the number of children that the respondents currently have, and the number of children they plan to have in the future. The estimate based on these details indicate that 27.5 percent of the women within the forty to forty-four age group do not have and do not plan to have any children in the future. Since this additional estimate generates a result that is of the same order of magnitude as the earlier one, we can reasonably believe that indeed a very high percentage of the women in Hong Kong will never have any children. ${ }^{6}$

6. Another robustness test is to look at the proportion of childless men in the population. By using a methodology similar to that which we have applied to women, we estimate that 36.85 to 38.5 percent of the men in the forty-one to forty-five age group in 2006 do not have children. This confirms the notion that many families in Hong Kong will remain childless. The reason why there is a range for the estimate is that the census database only reports the number 
The prevalence of childless families is a common phenomenon that goes far beyond Hong Kong's borders. Based on data from China's 20051 percent population census, my preliminary estimate indicates that 25.7 percent of women in Chinese cities will remain childless when they reach the age of fifty. This ratio is likely to be much higher in major cities such as Beijing and Shanghai. ${ }^{7}$ From table 10.1 the TFRs for Japan and the four Asian dragons are close to one. Since many women in these economies have more than one child, but the average number of children per woman is around one, the proportion of those who are childless cannot be negligible.

Childlessness is prevalent not only in Asia, but also in the West. Even the United States, which has an exceptionally high TFR compared with other advanced economies, has a moderate, but nevertheless significant, voluntarily childless rate of 7 percent in 2002 (Abma and Martinez 2006). In Germany, 21 percent of the women of birth cohort 1960 do not have children. The childless rate for the birth cohort 1966 is estimated to be 29 percent. For university-educated women born in 1965, the rate is much higher at 38.5 percent (Dorbritz 2008). In Italy, it has been estimated that about one-fifth of the women born in 1965 will remain childless (Mencarini and Tanturri 2006). Among British women who have received university education, 25 percent of those born in 1970 will likely remain childless (Kneale and Joshi 2008). In fact, the European baby bust has attracted so much attention that the New York Times Magazine finds it newsworthy to publish an investigative cover story with the sensational title of "No Babies" (Shorto 2008).

Thus, the emergence of childless families is not an isolated event, nor can this be regarded as quantitatively trivial. The analysis of Hong Kong's experience is valuable because this can be regarded as a leading indicator for other economies whose TFRs have not yet reached the low levels of Hong Kong. In this chapter, I shall confine myself only to the causes of low or zero fertility rates, but not to their implications.

\subsection{Theoretical Framework}

In this section, I shall briefly outline a theoretical model that is able to generate the demographic transition. The model is adapted from Ehrlich and

of children living in the household. It is well-known that some Hong Kong men have married women in the Chinese mainland, and their children have not migrated to Hong Kong yet. Thus, in our estimation, we have to take into account the number of men who are married, but whose wives and children are not in the household in Hong Kong. Since husbands tend to be older than wives, it is no surprise that the proportion of childless men is larger than that of childless women in the same age group. The corresponding estimate for the proportion of childless men in 2001 is between 27.83 to 29.02 percent.

7. See tables 8.2a and 8.3a of China National Bureau of Statistics (2007). According to the 20051 percent population Census in China, the TFRs of Beijing and Shanghai are 0.617 and 0.643 , respectively. Although some underreporting might have occurred because of the onechild policy in China, these extremely low TFRs imply that childless rates in these two cities could be higher than 35 percent. 
Lui (1991), modified in such a way that it can accommodate zero fertility. It is presented here to provide a theoretical foundation for the main hypotheses to be tested in the next section.

Consider an overlapping-generations economy where all the agents live for three periods: 0,1 , and 2 . In period 0 , the person is a child and does not make any decisions. In period 1, the person is a young working adult who has to decide how many children she should bear, how much time she should invest in the human capital of each of her children, and how much she should save for retirement. She is obligated to support her parent if still alive. She also acts as a "companion" for her parent, in the sense that her being around would give psychological pleasure to the parent. Even though each person lives for at most three periods, the economy can last forever because some agents are born in each period. In period 2, the agent does not work anymore. She gets material support from her children and her own savings. In addition, she can derive utility both from the quantity and quality of her children.

Let the production function of human capital be ${ }^{8}$

$$
H_{t+1}=A\left(H_{t}+H^{*}\right) h_{t}
$$

where $H_{t}=$ human capital of a representative working adult at time $t$; $H_{t+1}=$ human capital of a representative working adult in the next generation at time $t+1 ; H^{*}=$ raw labor (which implies that even if $H_{t}=0, H_{t+1}$ can still be bigger than zero); $h_{t}=$ the proportion of time that a representative parent at time $t$ invests in the human capital of each child; and $A=$ technology parameter in the production of human capital.

Consumption of a young adult at time $t$ and the consumption when she is old at time $t+1$ are given by

$$
\begin{aligned}
c_{1}(t) & =\left(H_{t}+H^{*}\right)\left(1-v n_{t}-h_{t} n_{t}-s_{t}\right)-\pi_{2} w H_{t} \\
c_{2}(t+1) & =\left[\pi_{1} n_{t} w H_{t+1}+B\left(H_{t}+H^{*}\right) s_{t}^{m}\right]+\mu\left(\pi_{1} n_{t}\right) H_{t+1}^{\alpha} .
\end{aligned}
$$

Each young adult has 1 unit of time. If he or she uses the entire unit to produce the consumption good, output is $H_{t}+H^{*}$. Even when $H_{t}=0$, raw labor $H^{*}$ can make output bigger than 0 . The number of children borne by a young parent at time $t$ is $n_{t}$. The proportion of time spent on raising a child is $v$. Thus, $v n_{t}$ is the proportion of time spent on the $n_{t}$ children. In addition, educating $n_{t}$ of them requires $h_{t} n_{t}$ units of time. Saving rate as a proportion of his or her maximum possible income is represented by $s_{t}$. The amount of consumption good provided by a representative young adult to support his parent at time $t$ is given by $w H_{t}$. The rate committed by the young adult to support his parent, $w$, is treated as exogenous here. ${ }^{9}$ The probability that a

8. This setup is similar to that in Becker, Murphy, and Tamura (1990).

9. This assumption is made for convenience and tractability only. It is possible to model it as the endogenous outcome of an implicit contract. 
young adult can survive to old age is $\pi_{2}$. The larger is $\pi_{2}$, the longer is the life expectancy of people. The reason why $\pi_{2}$ is included in the term $\pi_{2} w H_{t}$ is that a young adult does not have to pay for the old-age support of his parent if they have not survived. Hence, $\pi_{2} w H_{t}$ can be interpreted as the expected support for the parent.

The expression for $c_{2}(t+1)$ in equation (3) can be interpreted as a composite consumption good consisting of the material part (the terms within the square brackets), and the psychological "companionship" function. When an adult has turned old, each of his children will provide support equal to $w H_{t+1}$. Even though an adult has given birth to $n_{t}$ children, some of them cannot survive to adulthood. The probability that a child can survive to adulthood and has the chance to work is given by $\pi_{1}$. The second term inside the square brackets is total returns from the agent's savings, where $B>0$ and $0<m<1$. The last term in equation (3) is meant to capture the assumption that the quantity and human capital of his or her children can be treated as a utility-generating consumption good. The parameter $\mu$ can vary across different people. A large $\mu$ means that the person likes children very much. ${ }^{10}$ We also impose the restrictions that $0<\alpha<1$.

The utility function of a young adult at time $t$ is given by

$$
u_{t}=\frac{\left(c_{1}(t)^{1-\sigma}-1\right)}{(1-\alpha)}+\delta \pi_{2} \frac{\left(c_{2}(t+1)^{1-\sigma}-1\right)}{(1-\sigma)},
$$

where $\delta$ represents the discount rate for future consumption. Since the chance for an adult to survive to old age is $\pi_{2}$, we have to multiply old-age utility by $\delta \pi_{2}$. We impose the restriction that $0<\sigma<1$.

A representative young adult maximizes equation (4) subject to equations (1), (2), (3), and nonnegativity constraints for the choice variables $s_{t}, h_{t}$, and $n_{t}$. The first-order conditions are given by the following:

$$
\begin{aligned}
& \left(\frac{c_{2}}{c_{1}}\right)^{\sigma}=\frac{\delta \pi_{2} m B}{s_{t}^{l-m}} \equiv \delta R_{s} \\
& \left(\frac{c_{2}}{c_{1}}\right)^{\sigma} \geq \delta A \pi_{1} \pi_{2} w[1+\alpha N] \equiv \delta R_{h} \\
& \left(\frac{c_{2}}{c_{1}}\right)^{\sigma} \geq \delta A \pi_{1} \pi_{2} w[1+N]\left[\frac{h_{t}}{\left(v+h_{t}\right)}\right] \equiv \delta R_{n}, \\
& \text { where } N \equiv \mu w^{-1} H_{t+1}^{\alpha-1} .
\end{aligned}
$$

The left-hand sides of equations (5) to (7) can be interpreted as the marginal rate of substitution between period 1 and period 2 consumptions. The notations $R_{s}, R_{h}$, and $R_{n}$ represent the rates of return to savings, investment

10. We assume that $\mu$ is positive in the analysis. If a person dislikes children, we can actually treat $\mu$ as negative. 
in human capital, and investment in quantity of children, respectively. There are some useful properties of this model that can help us to understand the process of economic development and demographic transition. Suppose that in the beginning, life expectancy is low; that is, $\pi_{1}$ and $\pi_{2}$ are relatively small. From equations (6) and (7), the rates of return to investment in quantity and quality of children are low. The economy could be trapped in a zero-growth stagnant equilibrium with no change in human capital over time. Now assume that $\pi_{1}$ and $\pi_{2}$ go up sufficiently. Since both $R_{h}$ and $R_{n}$ increase as a result, parents tend to invest more in both quantity and quality of children. Consequently, both $n_{t}$ and $H_{t+1}$ rise. However, as the human capital stock for the next generation has gone up, its opportunity cost of having children increases as well. ${ }^{11}$ In that generation, the parent would reduce the quantity of children, but continue to invest in human capital. As the level of human capital of the parents in each subsequent generation rises, the economy continues to grow, but fertility rate declines. This is the demographic transition.

It should be noted that as $H_{t+1}$ increases during the process of economic development, the term $N$ defined in equation (8) will converge to zero because $0<\alpha<1$. From equations (6) and (7), it can be shown that $R_{h}>R_{n}$ if and only if $N^{-1}>(1-\alpha)\left[\left(h_{t} / v\right)-\alpha /(1-\alpha)\right]$. Since the left-hand side of this inequality goes up without bound, at some stage of economic development, $R_{h}$ must exceed $R_{n}$. This means that equality for equations (6) and (7) cannot hold simultaneously. There is an interior solution for $h_{t}$, but $n_{t}$ has a corner solution, in the sense that it should attain the smallest admissible value. $^{12}$

This immediately poses a problem. What is the lowest admissible value for $n_{t}$ ? The first candidate is that it is equal to one, and the second is zero. We should note that if the number of children is zero, it will be futile for the adult to invest in human capital of the children because they do not exist. Consumptions defined in equations (2) and (3) collapse to simpler terms. The person does not have to spend any resources in raising and educating children. During retirement, his or her consumption comes from savings only. There is no financial support from the children and no utility from companionship. On the other hand, if the person chooses to have one child, he or she can continue to invest in the human capital of that child. Equations (5) and (6) are still the laws of motion determining the dynamics of the variables in the model. The decision of whether to choose zero or one can be made by directly computing the utility after substituting the relevant values of $n_{t}$ and other variables into equation (4). Assume that an agent has chosen

11. Actually the opportunity time cost of investing in human capital also rises, but from equation (1), the higher human capital stock of the parent will make him or her more effective in producing human capital. This mitigates the rise in time cost.

12. From equation (5), since a sufficiently small saving rate can cause the rate of return to savings to go up to some large value, the saving rate always has an interior solution. 
to have one child. We can demonstrate by simulation exercises that as the human capital of his or her descendants grows over time, the latter may find it more advantageous to shift over to zero children. The timing of the shift depends on the parameters of the model. In particular, if companionship is viewed as important; that is, $\mu$ is relatively big, it will be less likely for the family to arrive at either the corner solution of one or zero. After the shift to the new corner solution, this dynastic family will terminate.

The model discussed previously provides a coherent framework that generates a number of testable hypotheses. The most important of these is the Demographic Transition Hypothesis: In an economy that has entered a perpetual growth equilibrium, total fertility rate of the potential parent is negatively related to his or her human capital.

To test the demographic transition hypothesis, we have to introduce a number of control variables, some of which are interesting on their own. The model can guide us in identifying the proper controls. From equation (7), an increase in $v$ will lower the return to the quantity of children. This leads us to the Opportunity Cost Hypothesis: When a parent finds it more costly to raise children, he or she will have fewer of them.

From equations (6) and (7), an increase in the educational technology parameter $A$ will raise not only the return to investment in human capital, but also the return to the quantity of children. Hence, we have the Educational Technology Hypothesis: The more effective a parent is in educating his or her children, the greater is the quantity of children she wants to raise.

Equation (7) includes an old-age support parameter w. It follows from the equation that when w goes up, the return to quantity of children will also rise. We can state the Old-Age Security Hypothesis as follows: If a person's old-age security motive is stronger, he or she will raise more children.

Both equations (6) and (7) contain a parameter, $\mu$, which is a measure of people's preference for children. This is another control variable that has to be included in our empirical analysis in the next section. It is beyond the scope of this chapter to explicitly model the factors affecting taste, since there is already an extensive literature on this issue in different branches of social science. For example, Koropeckyj-Cox and Pendell (2007) find that religiosity and attitudes about marriage and gender equality can affect women's acceptance of childlessness. Barber and Axinn (2004) reports that exposure to mass media influences can change people's childbearing behaviors and preferences for smaller families. Schmidt (2008) provides evidence showing that attitudes toward risks can also affect a woman's fertility decision. Thus, the literature and the theoretical model of this chapter both indicate that we should incorporate preference variables as controls in our regressions. Another advantage of including preference variables is that we can quantitatively assess their relative importance in determining a woman's fertility. 


\subsection{Empirical Results}

This section presents and discusses the main empirical findings. I shall first explain the choice of the data set used and provide summary statistics of the data. Then empirical tests based on a Tobit model and a generalized Poisson model are presented and the economic interpretations discussed. I shall then use a Probit model to focus more sharply on the choice of whether or not to have children at all. For reasons to be explained later, despite the fact that the Probit estimator is less efficient than the Tobit, the results generated by the former can still provide us with additional insights. Finally, a number of dummy variables have been used in all the regressions. The meanings of the estimated results on these dummies are discussed.

\subsubsection{Choice of Data Set and Summary Statistics}

To test the basic hypotheses outlined in the previous section and to generate additional results, the official census (or by-census) data conducted in Hong Kong once every five years would be a good data source. The 5 percent sample contains microdata for more than 110,000 households and 340,000 individuals. Although the large number of observations can give us greater flexibility in the estimations, there are also important shortcomings. Since it only tells us how many children a parent has already had, but not the number of children he or she wants to raise in the future, we have to rely on more indirect methods of estimation such as survival analysis. Moreover, there are many possible determinants of fertility that are simply not included in the census database. ${ }^{13}$

In this chapter, I have chosen to estimate the results using a data set generated from a randomized survey I conducted. Details of the survey are provided in the appendix. In addition to having more specific information on fertility behaviors, the survey contains an important new variable, the number of additional children the respondent plans to have. We can add up the value of this variable with the number of children that the respondent has already had. This would generate the total number of desired total fertility rate, which is the main dependent variable to be explained in this chapter. Given this information, we can also easily construct a dichotomous variable (FERTDUMMY) on whether the respondent wants to have zero, or a positive number, of children.

Table 10.4 contains summary statistics of some key variables from the survey data set. It should be noted that we had set constraints on two variables; namely, approximately three-quarters of the respondents should be women and the targeted age group twenty to forty-five years old (child-bearing

13. It does not mean that empirical estimations using census data are of no value. A separate project with similar objectives using census data has been conducted by the author. 
Table 10.4

Summary statistics of the survey data

Number of respondents

1,017

Ratio of female to male respondents

794: 223

Number of never married respondents

622

Median age of respondents

Number of respondents who do not want anymore children

409

Number of respondents who have no children

705

Median number of total desired children

2

Median number of years of schooling

Median years of working experience

Median years of experience for those currently employed

Median monthly income of all respondents in HK\$

Median monthly income of employed respondents in HK\$

Number of homeowners

Median size of home in square feet

age). ${ }^{14}$ Other than these, the respondents were chosen randomly. Because of the constraints, the respondents were on average considerably younger than the median age of the Hong Kong population, thirty-nine. Other summary statistics in table 10.4 appear to be consistent with the general profiles of these types of people in Hong Kong. For example, the number of years of schooling for these people is higher than the average person in the population, which consists of many less educated older people. Similarly, the low number of years of working experience also reflects the young age of the targeted group. It can also be seen that the majority of the respondents do not have children, and many of them do not want to have children in the future.

\subsubsection{Verification of the Demographic Transition}

According to the model of demographic transition discussed in the previous section, total fertility rate, which is represented here by the variable TFR and defined as the actual number of children plus expected number of children in the future, should go down over time when parents become more and more educated. This longitudinal phenomenon can be captured here by cross-sectional data, if we assume that adults having different levels of human capital at a given point in time are similar to those who belong to different stages of economic development over time. Moreover, the pos- 
sibility of having corner solutions for fertility; that is, TFR equals to zero, means that the fertility data are censored at zero. A convenient approach to deal with this phenomenon is to use a Tobit model where the dependent variable, desired TFR, is censored at zero. The general formulation for Tobit is given by

$$
\begin{array}{rlrl}
y_{t}^{*} & =\boldsymbol{x}_{i}^{\prime} \boldsymbol{\beta}+\varepsilon_{i} \\
y_{i} & =0 & & \text { if } y_{i}^{*} \leq 0, \\
y_{i} & =y_{i}{ }^{*} & \text { if } y_{i}^{*}>0,
\end{array}
$$

where $y_{i}$ is the dependent variable, $\boldsymbol{x}_{i}$ is a vector of the explanatory variables, $\boldsymbol{\beta}$ is the vector of coefficients of the variables, and $\varepsilon_{i}$ is an error term with standard normal distribution.

Table 10.5 presents the summary of several regressions aimed at identifying the determinants of fertility in Hong Kong. ${ }^{15}$ The benchmark regression is the Tobit model in regression (1), where the standard errors are obtained by using the robust estimators of Huber (1967) and White (1980). The error term in this regression does not have to be identically distributed. ${ }^{16}$

Two measures of human capital, years of schooling (SCHOOLING) and years of working experience (EXPERIENCE), are used. I have also added the square of these two variables into the regression to capture possible nonlinearity in these variables. The estimated coefficients for these four variables are all statistically significant. Moreover, despite the positive signs of the coefficients for the squared variables, within the value ranges of SCHOOLING and EXPERIENCE, desired TFR is always negatively related to these measures of human capital. This result supports the Demographic Transition Hypothesis discussed in section 10.3. As the human capital of the potential parent increases, they tend to have fewer or even no children. We should note that the negative effect of SCHOOLING on desired TFR is quantitatively much larger than that of EXPERIENCE. Other things equal, an adult who has fourteen years of schooling would have 1.24 fewer children compared to one who has no education at all. ${ }^{17}$

The positive effect of marriage on desired TFR is consistent with the Opportunity Cost Hypothesis. Because of economy of scale, married people would be more efficient in raising children. This is similar to the effect of lowering $v$ modeled in section 10.3. We expect that the desired TFRs of

15. To mitigate possible endogeneity problems, I have also tried various instrumental variable estimators in the regressions. However, the Wald exogeneity tests applied to these regressions indicate that endogeneity is not a problem. In fact, the results reported in tables 10.5 and 10.6 generally remain robust when instrumental variables are used.

16. If we do not use the robust estimator for the standard errors, as expected, the results are more significant.

17. To compute marginal effects in the censored regression model, we need the ratio of the uncensored observations to the total number of observations. In this case, it is equal to 0.841 . See Greene (2003, 765). 


\begin{tabular}{|c|c|c|c|c|}
\hline & $\begin{array}{c}\text { (I) Tobit } \\
\text { Dependent } \\
\text { Variable }= \\
\text { Desired TFR }\end{array}$ & $\begin{array}{l}\text { (II) Generalized } \\
\text { Poisson } \\
\text { Dependent } \\
\text { Variable }= \\
\text { Desired TFR }\end{array}$ & $\begin{array}{c}\text { (III) Probit } \\
\text { Dependent } \\
\text { Variable }= \\
\text { FERTDUMMY }\end{array}$ & $\begin{array}{c}\text { (IV) OLS } \\
\text { Dependent } \\
\text { Variable = } \\
\text { Desired TFR }\end{array}$ \\
\hline Constant & $\begin{array}{l}2.95582 * * * * \\
(0.73271)\end{array}$ & $\begin{array}{l}1.60520 * * * * \\
(0.38530)\end{array}$ & $\begin{array}{c}2.07478^{*} \\
(1.29690)\end{array}$ & $\begin{array}{l}2.78667 * * * * \\
(0.64604)\end{array}$ \\
\hline INCOME & $\begin{array}{c}0.0000043 \\
(0.0000047)\end{array}$ & $\begin{array}{l}0.000008^{* * * * *} \\
(0.000002)\end{array}$ & $\begin{array}{c}0.0000072 \\
(0.0000089)\end{array}$ & $\begin{array}{c}0.000003 \\
(0.000004)\end{array}$ \\
\hline MARRIED DUMMY & $\begin{array}{l}0.46078^{* * * * *} \\
(0.09089)\end{array}$ & $\begin{array}{l}0.24701 * * * * \\
(0.04714)\end{array}$ & $\begin{array}{l}1.07197^{* * * * *} \\
(0.20328)\end{array}$ & $\begin{array}{l}0.35063^{* * * * *} \\
(0.07555)\end{array}$ \\
\hline AGE & $\begin{array}{l}-0.02126^{* * * *} \\
(0.00757)\end{array}$ & $\begin{array}{l}-0.01470 * * * * \\
(0.00397)\end{array}$ & $\begin{array}{l}-0.05604 * * * * \\
(0.01573)\end{array}$ & $\begin{array}{l}-0.01432^{* * *} \\
(0.00652)\end{array}$ \\
\hline SCHOOLING & $\begin{array}{l}-0.20422^{* * *} \\
(0.10287)\end{array}$ & $\begin{array}{l}-0.14388^{* * * * *} \\
(0.05214)\end{array}$ & $\begin{array}{c}0.00997 \\
(0.17742)\end{array}$ & $\begin{array}{l}-0.18473^{* * *} \\
(0.09141))\end{array}$ \\
\hline $\mathrm{SCHOOLING}^{\wedge} 2$ & $\begin{array}{l}0.00709^{* *} \\
(0.00370)\end{array}$ & $\begin{array}{l}0.00462^{* * * * *} \\
(0.00190)\end{array}$ & $\begin{array}{l}-0.00014 \\
(0.00623)\end{array}$ & $\begin{array}{l}0.00642 * * \\
(0.00329)\end{array}$ \\
\hline EXPERIENCE & $\begin{array}{l}-0.02758 * * * * \\
(0.00752)\end{array}$ & $\begin{array}{l}-0.01235^{* * * *} \\
(0.00400)\end{array}$ & $\begin{array}{l}-0.03329 * * \\
(0.01866)\end{array}$ & $\begin{array}{l}-0.0239 * * * * \\
(0.00647)\end{array}$ \\
\hline EXPERIENCE^2 & $\begin{array}{l}0.000108^{* * * *} \\
(0.000038)\end{array}$ & $\begin{array}{l}0.000046^{* * *} \\
(0.000021)\end{array}$ & $\begin{array}{c}0.00033 \\
(0.00038)\end{array}$ & $\begin{array}{l}0.00009^{* * * *} \\
(0.00003)\end{array}$ \\
\hline SIBLINGS & $\begin{array}{l}0.06384 * * * * \\
(0.01993)\end{array}$ & $\begin{array}{l}0.00730 \\
(0.01039)\end{array}$ & $\begin{array}{l}0.13163^{* * * * *} \\
(0.04434)\end{array}$ & $\begin{array}{l}0.05039^{* * * *} \\
(0.01724)\end{array}$ \\
\hline TRAFFIC TIME & $\begin{array}{l}-0.05215^{*} \\
(0.03723)\end{array}$ & $\begin{array}{l}-0.03168 * * \\
(0.01849)\end{array}$ & $\begin{array}{l}-0.14216^{* * *} \\
(0.06857)\end{array}$ & $\begin{array}{l}-0.04056^{*} \\
(0.03197)\end{array}$ \\
\hline HOUSE SIZE & $\begin{array}{l}0.000216^{* * *} \\
(0.000103)\end{array}$ & $\begin{array}{l}0.00017 * * * * \\
(0.000048)\end{array}$ & $\begin{array}{l}-0.0000028 \\
(0.00021)\end{array}$ & $\begin{array}{l}0.000199 * * * \\
(0.00009)\end{array}$ \\
\hline $\begin{array}{l}9 \text { DUMMIES (Results } \\
\text { presented in table 10.6) }\end{array}$ & & & & \\
\hline Number of observations & 929 & 929 & 929 & 929 \\
\hline Wald $\chi^{2}$ & 235.11 & 288.77 & 153.02 & \\
\hline $\begin{array}{l}\text { Prob }>\chi^{2} \\
\ln \sigma\end{array}$ & $\begin{array}{l}0.0000 \\
-0.12738^{* * * * *} \\
(0.03920)\end{array}$ & 0.0000 & 0.0000 & \\
\hline$\delta$ & & $\begin{array}{l}-0.42616 * * * * \\
(0.03149)\end{array}$ & & \\
\hline $\begin{array}{l}\text { Pseudo } R^{2} \\
R^{2}\end{array}$ & & 0.0852 & 0.2963 & 0.2324 \\
\hline
\end{tabular}

Notes: Terms inside brackets are standard errors estimated by the method of White (1980) and Huber (1967).

**** Significant at the 1 percent level for one-tail test.

*** Significant at the 2.5 percent level.

** Significant at the 5 percent level.

* Significant at the 10 percent level. 
married people are higher. The negative effect of age on desired TFR may be due to the nature of the dependent variable. Young adults may not fully realize the high cost of bearing, nurturing, and educating children and therefore may plan to have too many children. However, as they get older, they become more realistic about the cost. ${ }^{18}$ The time it takes to travel to work competes for resources that can be provided to the children. The negative effect on TRAFFIC TIME again provides support to the Opportunity Cost Hypothesis.

The positive impact of the number of siblings of the parent may be due to economy of scale. Siblings themselves sometimes can help out in babysitting and their children can be convenient playmates of one's own children. The result again supports the Opportunity Cost Hypothesis. ${ }^{19}$ This phenomenon may cause long-term effect for future generations. As the average size of the core family is decreasing due to the low TFR, future parents will have fewer siblings of their own. That will in turn weaken their intent to bear children.

It is well known that population density in Hong Kong is among the highest in the world, with the result that its residents have to live in relatively small quarters. According to the results in table 10.5, the small size of Hong Kong's residential quarters is likely one of the factors causing the low TFR there. This is consistent with the findings in a recent paper by Murphy, Simon, and Tamura (2008), which provides evidence indicating that population density, or price of space, is negatively correlated with fertility rate in the United States. Given the likely scenario that housing in Hong Kong will continue to be expensive, the marginal cost of raising children will remain high.

Assuming that children are normal goods, we should expect some positive effect of income on fertility rate. However, the results of the Tobit regression in table 10.5 indicate the income effect is quantitatively rather small and statistically insignificant. ${ }^{20}$ One may suspect that the apparent absence of significant income effect is due to problems inherent in the Tobit estimation, which presupposes that the error term is normally distributed. However, the dependent variable - desired total fertility rate-consists of discrete integers. An alternative approach is to rely on a count model. By doing so, we can also check the robustness of the other results obtained by the Tobit model.

18. Heaton, Jacobson, and Holland (1999) study how intended childlessness changes over time. Our finding that intended fertility declines as age goes up is consistent with this early study. If we use the actual number of children as the dependent variable, then the evidence indicates that this is positively related to age.

19. Parr (2005) also finds that the number of siblings of a parent is positively related to her own fertility rate.

20. Income data from the survey has been modified to reduce possible biases in the estimation of income effect. For married respondents whose reported personal income is zero (most of them being housewives), we use the income of spouse instead of the person's own income. 
A convenient count model that can be used is the Poisson model. However, this has the restrictive property that the expected number of children would be equal to the variance of the number of children. To mitigate this problem, we employ a generalized Poisson model, which is more flexible. The probability mass function of this model is ${ }^{21}$

$$
f\left(y_{i} ; \lambda_{i}, \delta\right)=\frac{\left[\lambda_{i}\left(\lambda_{i}+\delta y_{i}\right)^{y_{i}-1} e^{-\lambda_{i}-\delta y_{i}}\right]}{y_{i} !}
$$

for $y_{i}=0,1,2, \ldots$, and $\ln \lambda_{i}=\boldsymbol{x}_{i}^{\prime} \boldsymbol{\beta}$. If the parameter $\delta=0$, then equation (10) reduces exactly to the probability mass function of the usual Poisson model. It can be shown that

$$
\begin{aligned}
E\left[y_{i} \mid \boldsymbol{x}_{i}\right] & =\frac{\lambda_{i}}{(1-\delta)}, \\
\operatorname{Var}\left[y_{i} \mid \boldsymbol{x}_{i}\right] & =\frac{E\left[y_{i} \mid \boldsymbol{x}_{i}\right]}{(1-\delta)^{2}} .
\end{aligned}
$$

Results of the generalized Poisson estimation are presented in regression (II) of table 10.5.22 It can readily be seen that the coefficient for the income variable, though very small, is statistically significant and positive, thus supporting the hypothesis that children are normal goods. ${ }^{23}$ All other results are similar to those in the Tobit estimation, with the exception that the coefficient for the size of living quarters is not significant. The core story for demographic transition remains clear and valid. Thus, the results in the benchmark regression (I) appear to be robust. In (IV) of table 10.5, we also report results from an ordinary least squares (OLS) estimation. Again, we find results similar to the Tobit estimation.

If we substitute the median values of all the relevant variables into regression (I), we can readily show that quantitatively, the most powerful factor causing the decline in desired TFR is SCHOOLING. But the median years of schooling of the Hong Kong population is considerably below those in highly developed economies. What are the other factors that contribute to the low or zero fertility in Hong Kong? In all the regressions in table 10.5 , I have added nine dummy variables, each representing the respondent's subjective assessment of different factors that may affect fertility. These variables, acting as controls, considerably sharpen the estimations for the

21. See Hardin and Hilbe (2007) and Wang and Famoye (1997).

22. Since the estimated $\delta$ in regression (III) is negative, there is "underdispersion" in the data.

23. The marginal effect of an increase in income on fertility rate in the generalized Poisson model can be estimated by making use of the incidence rate ratio. To induce a person having one child to have another one, his or her monthly income has to be increased by more than HK $\$ 85,000$. In the survey conducted, there is a question asking the respondents to reveal how much government subsidy they would have to be paid in order that they were willing to bear one child more than what they wanted. The answer for most respondents was several million Hong Kong dollars. This seems to be consistent with the very small income effect estimated here. 
objective variables included in table 10.5. The results for these dummies also provide additional opportunities for us to test the hypotheses discussed earlier. Discussion of these dummies will be postponed to subsection 10.4.3, which follows.

\subsubsection{Childless Families}

The last subsection provides explanations for the occurrence of the demographic transition in Hong Kong. We now focus on the choice for zero fertility. The aforementioned Tobit and generalized Poisson models are appropriate tools for predicting fertility rates of different values, including zero. However, one can argue that the factors determining the choice between zero and positive fertility could be different from the decision on whether one should have even more children. The Tobit or generalized Poisson model does not recognize that the margin between zero and one could be different from, say, the margin between three and four children. Hence, there is some value in using a binary model to explicitly deal with the choice between zero and positive fertility.

A convenient approach is to construct a binary variable, FERTDUMMY, whose value is defined to be equal to one for a person who plans to have at least one child, and zero if he or she chooses not to have any children. The probability of the occurrence of childless families can be estimated by a Probit model, which can be represented by the following:

$$
\operatorname{Prob}(Y=1 \mid \boldsymbol{x})=\Phi\left(\boldsymbol{x}^{\prime} \boldsymbol{\beta}\right),
$$

where $Y$ is a dichotomous dependent variable that assumes the value of either 0 or $1, \Phi($.$) is the standard normal distribution function, \boldsymbol{x}$ is a vector of explanatory variables, and $\boldsymbol{\beta}$ is the vector of the corresponding coefficients. Estimation results of the Probit model are presented in regression (III) in table 10.5.

Before interpreting the results from the Probit estimation, we should note three things. First, the variables included in the two regressions are the same, which make comparisons between the two easier. Second, the error terms of both regressions are normally distributed. Third, by using a single value of one to represent different quantities of children, the Probit method loses some information that is available to the Tobit estimator. This makes Probit a less efficient estimator. Despite this, comparison of regressions (I) and (III) readily indicates that most of the results obtained in the Tobit model remain intact in Probit. ${ }^{24}$ The exceptions are SCHOOLING, SCHOOLING^2, and HOUSE SIZE, which do not have significant results.

At this stage of economic development in Hong Kong, years of schooling seem to have stronger effects on the number of children beyond one than on

24. We have also tried a Logit model. The results are very similar to those in Probit and therefore not reported here. 
the decision of whether to have children at all. ${ }^{25}$ The average size of living quarters in Hong Kong seems to be able to accommodate a small family with one child. The cost of space for the first child may be low enough for it not to be an important concern. However, marginal cost of space for additional children may be much higher. That is why HOUSE SIZE is an important variable in the Tobit model, but much less so in Probit, which deals only with positive or zero fertility decisions.

\subsubsection{Subjective Assessment Variables}

In the regressions reported previously, I have included nine dummy variables as controls, but their results have been suppressed. This subsection discusses them. In the original survey, twenty questions related to the respondents' subjective views of the determinants of fertility were asked, and the answers were recorded as dummy variables. These answers provide nontrivial information on what the respondents regarded as important in affecting their own personal fertility decisions. The twenty dummies were all tried out, but finally I have included into the regressions only those that are statistically significant. Although some respondents had claimed that the other eleven factors were important, the statistical evidence does not support the claim and so they are excluded.

Table 10.6 reports the results on the nine included dummies. Some respondents believed that these were important factors and some did not. Among those who did, the statistical evidence shows that these factors would indeed make a difference in their decisions. Although I have only reported the estimations for regressions (I) to (III), the results are similar in the OLS regression (IV).

Quantitatively, the factor that seems to have the most powerful effect on fertility is whether the respondent liked children or not. This indicates that the preference parameter, $\mu$, which we discussed in section 10.3, is indeed a useful control. However, we should note that only 4.5 percent of the respondents claimed that they did not like children. This percentage is not big enough to explain the very low fertility rate in Hong Kong.

Estimations for other variables in table 10.6 can shed more light on fertility decisions. Variable (a) - negative impact on job and career - can be interpreted as part of the opportunity cost of having children. About one-third of the respondents regard this as an important factor. The negative sign of the parameter estimated again supports the Opportunity Cost Hypothesis.

Variables (b), (c), and (e) are related to the respondents' subjective evaluations of how efficient or confident they would be in meeting the obligations of raising and educating children. Apparently, a sizable proportion of people did not feel that they were prepared. These results support both

25. The theoretical explanation behind this phenomenon is being explored in another paper by this author. 
Results for the dummy variables on subjective assessment

\begin{tabular}{|c|c|c|c|c|}
\hline & From (I) Tobit & $\begin{array}{l}\text { From (II) } \\
\text { Generalized } \\
\text { Poisson }\end{array}$ & $\begin{array}{l}\text { From (III) } \\
\text { Probit }\end{array}$ & $\begin{array}{c}\text { Percentage of } \\
\text { answers with } \\
\text { dummy }=1\end{array}$ \\
\hline \multicolumn{5}{|c|}{ Factors that negatively affect my fertility decision: Yes $=1 ; \mathrm{No}=0$} \\
\hline $\begin{array}{l}\text { (a) Negative impact on my job } \\
\text { and career }\end{array}$ & $\begin{array}{l}-0.18370 * * * * \\
(0.06793)\end{array}$ & $\begin{array}{l}-0.06121^{* *} \\
(0.03527)\end{array}$ & $\begin{array}{l}-0.28677^{* * * *} \\
(0.12576)\end{array}$ & 32.6 \\
\hline $\begin{array}{l}\text { (b) No confidence in } \\
\text { educational system }\end{array}$ & $\begin{array}{l}-0.14572 * * * \\
(0.06863)\end{array}$ & $\begin{array}{l}-0.06128^{* *} \\
(0.03545)\end{array}$ & $\begin{array}{l}-0.22817 * * \\
(0.12287)\end{array}$ & 27.0 \\
\hline $\begin{array}{l}\text { (c) Don't know how to raise } \\
\text { children }\end{array}$ & $\begin{array}{l}-0.26491 * * * * \\
(0.08241)\end{array}$ & $\begin{array}{l}-0.17184^{* * * * *} \\
(0.04219)\end{array}$ & $\begin{array}{l}-0.41467^{* * * *} \\
(0.13671)\end{array}$ & 21.1 \\
\hline (d) Don't like children & $\begin{array}{l}-1.07425^{* * * * *} \\
(0.23034)\end{array}$ & $\begin{array}{l}-0.46225^{* * * *} \\
(0.08297)\end{array}$ & $\begin{array}{l}-0.97074^{* * * *} \\
(0.24338)\end{array}$ & 4.5 \\
\hline (e) No confidence in marriage & $\begin{array}{l}-0.24085^{* *} \\
(0.1256)\end{array}$ & $\begin{array}{l}-0.12819^{* * *} \\
(0.06291)\end{array}$ & $\begin{array}{l}-0.41780^{* * *} \\
(0.18717)\end{array}$ & 9.5 \\
\hline (f) Like children Factors that & $\begin{array}{c}\text { sitively affect my } \\
0.46071^{* * * *} \\
(0.07692)\end{array}$ & $\begin{array}{l}\text { ertility decision: } \\
0.12010^{* * * *} \\
(0.04214)\end{array}$ & $\begin{array}{l}s=1 ; N o=0 \\
0.77030^{* * * *} \\
(0.12632)\end{array}$ & 69.9 \\
\hline $\begin{array}{l}\text { (g) Having children is part of } \\
\text { my social responsibility }\end{array}$ & $\begin{array}{l}0.23870^{* * * * *} \\
(0.08258)\end{array}$ & $\begin{array}{l}0.11025^{* * * *} \\
(0.04018)\end{array}$ & $\begin{array}{l}0.34071^{* *} \\
(0.18914)\end{array}$ & 16.0 \\
\hline $\begin{array}{l}\text { (h) Raise children to secure } \\
\text { old-age support }\end{array}$ & $\begin{array}{c}0.14859^{*} \\
(0.09992)\end{array}$ & $\begin{array}{l}0.19844 * * * * \\
(0.04588)\end{array}$ & $\begin{array}{c}0.15119 \\
(0.18264)\end{array}$ & 14.6 \\
\hline \multicolumn{5}{|c|}{ If you don't have children, what will you do to protect your retirement? } \\
\hline $\begin{array}{l}\text { (i) Don't know what to do }=1 \text {; } \\
\text { otherwise }=0 \text {. }\end{array}$ & $\begin{array}{l}0.32013 * * * \\
(0.15618)\end{array}$ & $\begin{array}{l}0.13867 * * \\
(0.07107)\end{array}$ & $\begin{array}{c}0.15278 \\
(0.30129)\end{array}$ & 6.0 \\
\hline
\end{tabular}

****Significant at the 1 percent level for one-tail test.

***Significant at the 2.5 percent level.

**Significant at the 5 percent level.

*Significant at the 10 percent level.

the Opportunity Cost Hypothesis and Educational Technology Hypothesis. Variable (g) indicates that some respondents' decisions were dependent on the views of others. It is interesting to note that in the spring of 2005, the Chief Secretary of the Hong Kong government at that time, Donald Tsang, made a casual, but widely reported, public remark that women in Hong Kong should bear three children because too low a fertility rate could have negative social consequences. ${ }^{26}$ In a city where information dissemination by the media is rapid, many people would have remembered this well-known remark, and some (16 percent in our sample) would believe that giving birth to children was part of their social responsibility. Finally, Tobit and Poisson estimations for variables (h) and (i) indicate that for those people who have

26. Mr. Tsang told the author of this chapter, in an informal occasion subsequent to his remark, that the remark was indeed casual and that the government of Hong Kong would not adopt any policy to encourage higher fertility. 
strong old-age security motives, it is more likely for them to increase the quantity of children. This supports the Old-Age Security Hypothesis.

Although the primary purpose of including these dummies as control variables is to sharpen the estimations for other variables, we have also obtained more evidence to support the hypotheses discussed in section 10.3.

\subsection{Concluding Remarks}

In this chapter, I have used Hong Kong's experience to demonstrate that economies undergoing rapid demographic transition may end up having large percentages of women who choose not to bear any children. The serious implications of this possible outcome should be studied carefully.

I have shown that an extension of the Ehrlich-Lui (1991) model can naturally generate not only the demographic transition, but also zero fertility rates for some families. Based on this model, I have proposed several testable hypotheses related to the determinants of demographic transition. These hypotheses are tested by a Tobit model, a generalized Poisson model, and a Probit model, using data from a survey that I conducted. The empirical results make a lot of sense. The quantity-quality of children trade-off, which drives the demographic transition, clearly exists. Other variables, such as different measures of the cost of educating and raising children, number of siblings of the parents, preferences for children, sizes of residential quarters, and social responsibilities also play significant roles in determining total fertility rate.

A number of puzzles remain unexplained in this chapter. For example, the speed of the emergence of childless families in Hong Kong, and possibly in some Chinese cities and several other East Asian economies as well, seems to defy any form of culture-based explanations. Confucian values, which heavily influence East Asian countries, attach the highest importance to making dynastic families sustainable. Why is it that we find some of the world's lowest fertility rates in these economies? The findings in this chapter also suggest that heterogeneous preferences for children may be an important variable that should be explicitly modeled in future research.

\section{Appendix}

In this appendix, I shall present details of the survey, upon which the empirical results of this chapter are based.

The survey was conducted over a three-month period spanning from November 2007 to February 2008. Each respondent was requested to answer forty questions, but some of these could be broken down into several sub- 
questions. Some questions were similar to those asked in the Census conducted once every five years by the Hong Kong government, but there were also new questions introduced. Most of the questions were related to the socioeconomic and educational backgrounds of the respondents and their spouses. There were also specific categorical questions on the factors that the respondents deemed important in affecting their fertility decisions. A key question, not available in the Census, was the additional number of children the respondent would like to have. Before formally conducting the survey, the questions were tested on a small sample of respondents to identify potential problems and to make improvements. This chapter has not fully made use of the answers to all the questions.

The respondents were chosen randomly according to the following procedure. The research teams were sent to each of the eighteen official districts in Hong Kong. The number of respondents chosen in each district was proportional to the population distribution in that district. The research teams were instructed to focus on people who appeared to fall within the age range of twenty to forty-five. The research teams regularly reviewed the age distribution of the respondents to make sure that they were compatible with that of the general population in Hong Kong. We also decided that about three-quarters of the respondents should be women. The survey was conducted at different hours of the day and different days of the week in public areas of these eighteen districts. To enhance randomness, the research teams chose the nth person on sight in the area after finishing with a respondent. A cash coupon equivalent to HK $\$ 50$ was given to every correspondent who completed the questionnaires. The sample size of the survey is 1,017 observations.

After all the answers had been coded, the distributions of many socioeconomic variables were compared to those from the census data. We have not spotted major discrepancies.

\section{References}

Abma, J., and G. M. Martinez. 2006. Childlessness among older women in the United States: Trends and profiles. Journal of Marriage and Family 68 (4): 1045-56.

Barber, J. S., and W. G. Axinn. 2004. New ideas and fertility limitation: The role of mass media. Journal of Marriage and Family 66 (5): 1180-1200.

Becker, G. S., and R. J. Barro. 1988. A reformulation of the economic theory of fertility. Quarterly Journal of Economics 103 (1): 1-25.

Becker, G. S., K. M. Murphy, and R. Tamura. 1990. Human capital, fertility and economic growth. Journal of Political Economy 98 (5): S12-S37.

Blackburn, K., and G. P. Cipriani. 2002. A model of longevity, fertility and growth. Journal of Economic Dynamics and Control 26 (2): 187-204.

Boldrin, M., and L. E. Jones. 2002. Mortality, fertility, and saving in a Malthusian economy. Review of Economic Dynamics 5 (4): 775-814. 
Central Intelligence Agency, United States Government. The world factbook, 2008. Available at: https://www.cia.gov/library/publications/the-world-factbook/index .html.

Census and Statistics Department, Hong Kong SAR Government. 1996. 1996 Population By-Census 1\% sample dataset.

2001. 2001 Population Census 5\% sample dataset.

2006. 2006 Population By-Census 5\% sample dataset.

2007. Women and men in Hong Kong: Key statistics. Available at: http://www .bycensus2006.gov.hk/en/data/data2/index.htm.

China National Bureau of Statistics. 2007. 2005 Nian Quanguo 1\% Renkou Chouyang Diaochao Ziliao (Data from 1\% Sample National Population Census of 2005). Beijing: China Statistics Press.

Coale, A. J. 1987. Demographic transition. In The new Palgrave: A dictionary of economics, vol. 1, ed. J. Eatwell, M. Milgate, and P. Newman. London: MacMillan: 793-96.

Doepke, M. 2004. Accounting for fertility decline during the transition to growth. Journal of Economic Growth 9 (3): 347-83.

2005. Child mortality and fertility decline: Does the Becker-Barro model fit the facts? Journal of Population Economics 18 (2): 337-66.

Dorbritz, J. 2008. Germany: Family diversity with low actual and desired fertility. Demographic Research 19 (Jul.-Dec.): 557-97.

Dyson, T., and M. Murphy. 1985. The onset of fertility transition. Population and Development Review 11 (3): 399-440.

Easterlin, R. A. 1987. Fertility. In The new Palgrave: A dictionary of economics, vol. 2, ed. J. Eatwell, M. Milgate, and P. Newman. London: MacMillan: 302-307.

Ehrlich, I., and F. T. Lui. 1991. Intergenerational trade, longevity and economic growth. Journal of Political Economy 99 (5): 1029-59.

1997. The problem of population and growth: A review of the literature from Malthus to contemporary models of endogenous population and endogenous growth. Journal of Economic Dynamics and Control 21 (1): 205-42.

Greene, W. H. 2003. Econometric analysis, 5th ed. Upper Saddle River, NJ: Pearson Education, Inc.

Hardin, J. W., and J. M. Hilbe. 2007. Generalized linear models and extensions, 2nd ed. College Station, TX: Stata Press.

Heaton, T. B., C. K. Jacobson, and K. Holland. 1999. Persistence and change in decisions to remain childless. Journal of Marriage and the Family 61 (2): 531-39.

Huber, P. J. 1967. The behavior of maximum likelihood estimates under nonstandard conditions. In Proceedings of the fifth Berkeley symposium on mathematical statistics and probability, ed. L. M. LeCam and J. Neyman, 221-33. Berkeley: University of California Press.

Kalemli-Ozcan, S. 2003. A stochastic model of mortality, fertility, and human capital investment. Journal of Development Economics 70 (1): 103-18.

Kneale, D., and H. Joshi. Postponement and childlessness: Evidence from two British Cohorts. Demographic Research 19 (Jul.-Dec.): 1935-68.

Koropeckyj-Cox, T., and G. Pendell. 2007. The gender gap in attitudes about childlessness in the United States. Journal of Marriage and Family 69 (4): 899-915.

Mencarini, L., and M. L. Tanturri. 2006. High fertility or childlessness: Micro-level determinants of reproductive behaviour in Italy. Population 61 (4): 389-415.

Murphy, K. M., C. Simon, and R. Tamura. 2008. Fertility decline, baby boom and economic growth. Journal of Human Capital 2 (3): 262-302.

Parr, N. J. 2005. Family background, schooling and childlessness in Australia. Journal of Biosocial Science 37 (2): 229-43. 
Schmidt, L. 2008. Risk preferences and the timing of marriage and childbearing. Demography 45 (2): 439-60.

Shorto, R. 2008. No babies. New York Times Magazine, June 29, 34-41, 68.

Soares, R. R. 2006. The effect of longevity on fertility: Evidence from the Brazilian demographic and health survey. Journal of Population Economics 19 (1): 71-97.

Wang, W., and F. Famoye. 1997. Modeling household fertility decisions with generalized Poisson regression. Journal of Population Economics 10 (3): 273-83.

White, H. 1980. A heteroskedasticity-consistent covariance matrix estimator and a direct test for heteroskedasticity. Econometrica 48 (4): 817-30.

World Bank. 1984. Population change and economic development. New York: Oxford University Press.

Press.

Zhang, J., and J. Zhang. 2005. The effect of life expectancy on fertility, saving, schooling and economic growth: Theory and evidence. Scandinavian Journal of Economics 107 (1): 45-66.

\section{Comment Hongbin Li}

In this interesting chapter, the author examines demographic transition and growth both theoretically and empirically.

Theoretically, it adapts a Journal of Political Economy (JPE) paper by the author and a colleague (Ehrlich and Lui 1991) in a way that allows zero fertility. Its findings can be summarized in the following hypotheses:

- Demographic transition hypothesis: Total fertility rate of a potential parent is negatively related to his or her human capital.

- Opportunity cost hypothesis: When a parent finds it costly to raise children, he or she will have fewer of them.

- Educational technology hypothesis: The parent's fertility rate is positively related to how efficient he or she is educating his or her children.

- Old-age security hypothesis: If a person's old-age security motive is stronger, he or she will raise more children.

Drawing on census and survey data from Hong Kong, the chapter finds empirical evidence that support these hypotheses.

The chapter has many nice contributions. First, it has examined a very important issue in economic development. The theory and empirical evidence can potentially shed light on our understanding of how demographic transition happens and where it will end up for developing countries. Second, low fertility has become a very serious policy issue in Hong Kong. In fact, many people do not even get married, not to speak of having children.

Hongbin Li is a professor of economics in the School of Economics and Management at Tsinghua University. 